\section{Hover Over from Dover}

THE publicity for the opening of the first hovercraft service across the Channel on Thursday, August 1, was rather less than overwhelming. On July $31 \mathrm{HRH}$ Princess Margaret inaugurated the service by SRN-4 (Mountbatten), which is to cross six times a day between Dover and Boulogne. The preceding day British Rail, whose subsidiary Seaspeed/BR Hovercraft Ltd operates the service, took over a large group of journalists. Before proving its claim-that the hovercraft clips an hour off the conventional Dover-Boulogne ferry time-British Rail had wasted more than an hour on embarkation formalities at Dover for a known number of luggageless passengers. On this basis, BR's claim that London to Paris by hovercraft and train takes only five hours against eight by the Golden Arrow needs some justifying. So does its other claim, that British travellers can get to Boulogne for breakfast by hovercraft and so snatch 10 hours in a day on French soil. So they can, but only by spending the previous night in Dover. There is no connexion from London early enough to catch the departure of the first Seaspeed "flight" at 8.20 a.m.

The crossing by hovercraft was a very small proportion of the day's total travel, but it was what mattered. First impressions seemed to depend on what correspondents had been led to expect-very few had travelled by hovercraft before. Some had been expecting

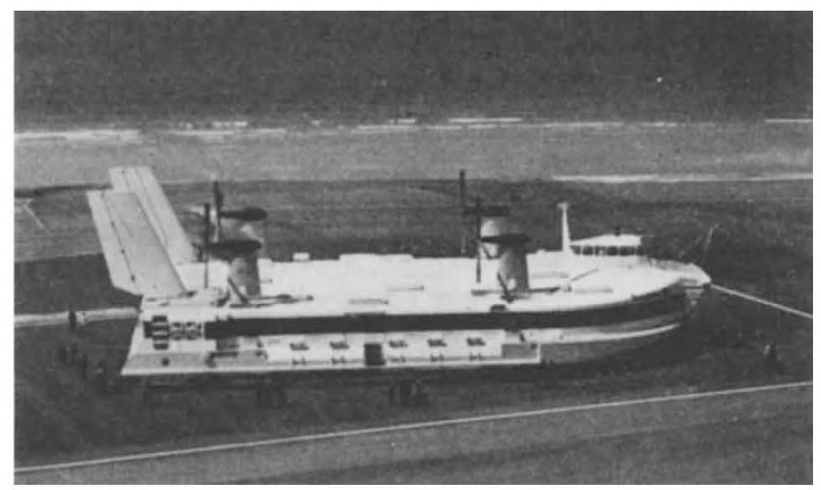

a very high noise level-like that in the SRN-6-a view almost completely obstructed by spray, and little motion. They were wrong on all counts.

The noise was quite tolerable for a 35 minutes exposure--it was possible to hear and to be heard. For less talkative passengers, the noise had a soporific effect, especially in the late afternoon. Its intensity falls between a noisy train and a noisy aircraft-it should not be compared with a jet aircraft in clear air, as its designer pointed out dryly. But the specially designed propellers had achieved a decrease of 15 decibels against the SRN-4, thanks to the lower tip speed. In any case, Princess Margaret was expected to suffer fewer decibels than the press, because various soundproofing measures were not then complete.

Conditions on July 30 were described as average for the Channel. There was a wind speed of 15 knots, a 4-5 foot sea and a slight swell abeam. In these conditions the craft kept up a steady 50 knots, picking up speed as soon as it cleared Dover harbour. The land/ sea transition was entirely imperceptible at both terminals. The passenger deck of the SRN-4 is some 10 feet from the ground with the craft at rest, and when the 8-foot skirt inflates before take-off the seated occupants are gently lifted another few feet. At this stage the skirt sometimes picks up a resonant frequency typical of a certain engine speed. A nasty throb develops and the craft jolts up and down like a horse at the trot. The sensation is quite disagreeable, but can be readily got over by use of the throttle. Out in the open sea the craft adopts a sort of irregular swivelling motion as the skirt moulds to the swell, but there is remarkably little spray. At intervals there is a check and shudder familiar to sailors as the eraft's nose "ploughs in" to an oncoming sea. A deeper skirt will iron out all these bumps, and the builders, British Hovereraft Corporation, look forward to 16-foot skirts for Channel operations, although it is not yet clear when these will be practicable. Meanwhile the present 8-foot skirt will enable the SRN-4 to operate in all but 1 per cent of Channel conditions, according to the chairman of British Rail Hovercraft Ltd, Dr Sydney Jones. British Rail is also considering other hoverferry routes, and Dr Jones suggested the Irish Sea. He said that the SRN-4 was an equally suitable craft for this crossing, and he doubted that Irish Sea conditions were systematically worse than the Channel, at least on the shorter routes. At the British Hovercraft Corporation consideration is being given to the building of 400 -ton and 1,000-ton hovercraft.

British Rail's SRN-4 across the Channel needs to be half full throughout the year to obtain a reasonable return on the investment. Much, of course, hangs on the craft's reliability. If it spends much time out of service for maintenance-and the first breakdown happened this week - a higher load factor will be necessary. At present the service relies on a single hovercraft, which must return to Dover for major repairs and inspections, because jacks have been installed only at the Dover end. A second craft would be ordered if the service warrants it, a decision typical of British Rail's attitude. The present SRN-4's internal configuration allows for 30 cars and 254 passengers. The number of car passengers (typically 3 per car) is expected to fill only a third of the seats, but rail connexions for the hovercraft service are to be provided only if there is a demand. It is hard to believe there is not. Compared with the squalor of the Channel boat service, the relative luxury of a booked seat by hovercraft even if it costs $£ 1$ more seems well worthwhile, without taking the potential time-saving into account.

\section{Graduates Who Never Were}

TECHNOLOGISTS are apparently more likely to abandon their degree courses before graduating than are students of pure science, the arts or social sciences. This disturbing trend is revealed in a report just published by the University Grants Committee (Enquiry into Student Progress 1968, HMSO, 37s. 6d.). The report, compiled from university records, analyses the success of all British students who would normally have been expected to graduate with first degrees in the summer of 1966.

There were 35,386 students in Great Britain who could have graduated in 1966, and of these $27,496(77 \cdot 7$ per cent) obtained first degrees at the normal time; 2,770 (7.8 per cent) obtained first degrees after a further year; 432 (1.2 per cent) were re-admitted in October 1967 , and $4,688(13 \cdot 3$ per cent) left university 
without obtaining a first degree. Only $1 \cdot 4$ per cent of the last group had failed thcir final examinations; most withdrew from their courses because of academic failure $(9.5$ per cent of the potential output), illness $(0.5$ per cent), disciplinary reasons $(0 \cdot 1$ per cent) or other unspecified reasons.

The largest proportion of abandoned courses were in engineering and technology; only 68 per cent of students graduated in the normal period, and a little over 76 per cent had done so by the following year. The percentages for medicine and dentistry were similar $(69$ and 65 per cent respectively), but in this case 87 per cent had obtained their first degree at the end of a further year. In the biological and physical sciences 80 per cent of students graduated at the normal time, and 85 per cent by the following year. Arts and social sciences had the highest rate of success; more than 80 per cent of the potential graduated in 1966 and by the following year the proportion was about 90 per cent.

More science and technology students withdrew through academic failure (10 per cent and almost 19 per cent respectively) than did arts (4.8 per cent) or social science students $(5.4$ per cent). Withdrawal for academic reasons was always greatest in the first year of courses. Illness, which was also greatest in the first year, caused the greatest number of withdrawals in the arts and social sciences. On the whole more men than women left for academic reasons, and a larger proportion of women left for "other reasons".

These trends are in general agreement with the findings of previous surveys of the progress of students entering universities in 1952, 1955 and 1957 carried out by the UGC (University Development 1957-62). The largest proportion of students who abandoned their courses were then as now technologists and pure scientists. Although direct comparison between the two sets of findings is difficult, it seems that the reduction from 14.2 to 13.3 per cent in the total population of students who failed to complete their courses is due to a reduction in the number who failed their finals; there has been no significant change in the proportion leaving for academic or other reasons.

\section{Gas on Tap}

There are signs that the Gas Council is on the way to winning its prolonged battle with the companies which have found gas in the North Sea. For a long time the gap between the two sides seemed unbridgeable, but now that a compromise has been reached with two of the companies, it seems that the Gas Council has the better of it. The argument, of course, is over price, and began when the companies asked for 5 pence a therm for the gas and the council offered $1 \cdot 8$ pence. Last week the Arpet group, one of the groups which has found gas in the Hewett Field, settled for a price of $2 \cdot 87$ pence per therm, on almost exactly the same conditions as Phillips accepted six months ago. Arpet has had little choice, in fact, because both finds were in the same field, and although the Arpet negotiators originally expressed disgust at the terms accepted by Phillips, they had in the end to accopt the same terms themselves. The contract signed last week assumes a 60 per cent load factor, and when the annual contract quantity is exceeded, the extra gas will be sold for 2.025 pence a therm. Like the Phillips contract, the Arpet agreement lasts for 25 years.
The two agreements will provide the Gas Council with some 600 million cubic feet of gas a day, about half the present daily demand in Britain. Rather more than half of this will be supplied by Phillips, rather less than half by Arpet. There are also signs of progress in the negotiations over the other major gas field, on the Leman Bank. The Gas Council has now negotiated with the Shell-Esso Group a temporary agreement to cover the supply of test gas from the Leman Bank field to the terminal at Bacton (see map). The price agreed for the interim contract is the same as the Arpet price, 2.87 pence per therm, and although this does not officially create a precedent for the full contract, which is to be signed by October 1, it may be significant. It is now being generally assumed that the Shell-Esso contract will differ only in detail from those signed by Phillips and Arpet. There will be some differences, because the Leman Bank is larger and farther out, and the gas it contains is free from sulphur, unlike the gas from the Hewett Field.

The council will be cheerful to have these contracts under its belt, although it is important to stress that the Shell-Esso agreement is only an interim measure to enable the council to test its pipelines and engineering facilities before the gas comes on to full stream next winter. Despite a price which must be disappointing

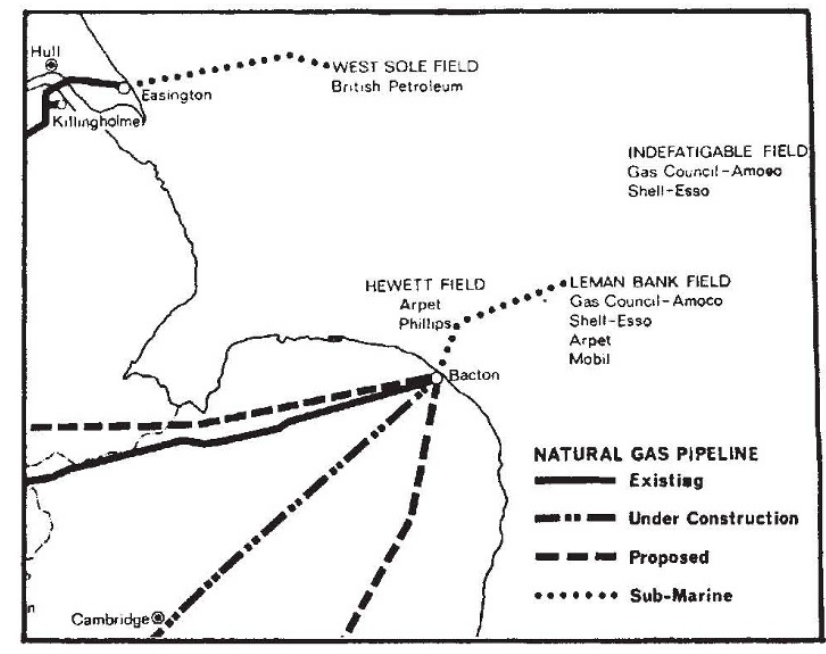

to the oil companies, there is no clear evidence that their enthusiasm for exploration in the North Sea is wilting. Meanwhile, the idea of setting up a National Hydrocarbons Corporation is again having an airing. This idea, originally put forward by a Labour Party group, would provide for a corporation with the power to search for oil and gas in the North Sea and act as a monopoly buyer for natural gas. If the corporation were set up, its crucial role would not arise until 197071, when the leases for some of the areas in the North Sea come up for renewal. This period will in any cace be interesting, because it will show whether the companies are still interested in prospecting, despite what they will undoubtedly regard as a low return.

\section{Creative Computers}

THere have been many science fiction stories since the beginning of the computer age nearly twenty years 